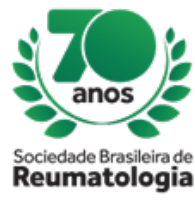

\title{
SUBGLOTTIC STENOSIS SECONDARY TO GRANULOMATOSIS WITH POLYANGIITIS: A CASE REPORT
}

Eduardo dos Santos Paiva (Hospital de Clínicas UFPR, Curitiba, PR, Brasil), Isadora Welter Pioresan (Hospital de Clínicas UFPR, Curitiba, PR, Brasil), Eldislei Mioto (Hospital de Clínicas UFPR, Curitiba, PR, Brasil), Pedro Coniã Szewczak Camelo (Hospital de Clínicas UFPR, Curitiba, PR, Brasil), Luan Felipe Luckmann (Hospital de Clínicas UFPR, Curitiba, PR, Brasil), Keoma Azevedo Sabião (Hospital de Clínicas UFPR, Curitiba, PR, Brasil), Nathan Catolino (Hospital de Clínicas UFPR, Curitiba, PR, Brasil), Ana Beatriz Artigas (Hospital de Clínicas UFPR, Curitiba, PR, Brasil), Ana Luisa Woidello (Hospital de Clínicas UFPR, Curitiba, PR, Brasil), André Andretta (Hospital de Clínicas UFPR, Curitiba, PR, Brasil), Mariana Lechitzki (Hospital de Clínicas UFPR, Curitiba, PR, Brasil), Bin Cheng Tan (Hospital de Clínicas UFPR, Curitiba, PR, Brasil), Victor Almeida Pontes (Hospital de Clínicas UFPR, Curitiba, PR, Brasil), Giovanna Lemes Leão (Hospital de clínicas UFPR, Curitiba, PR, Brasil)

\section{BACKGROUND}

Granulomatosis with polyangiitis, also known as Wegener's granulomatosis, is a vasculitis that affects small and medium-size vessels presenting necrotizing inflammatory granulomas. Its etiology is unknown, affecting mostly caucasian people, with no sex preference and an average onset age between 25 and 50 years old.

Classically, granulomatosis with polyangiitis have an effect on the upper airway, lungs and kidneys, clinical manifestations can vary from limited to multisystemic. Granulomatous inflammation of the upper airway mucosa occurs in nearly $95 \%$ of cases, with symptoms like nosebleeds, palate and nose septum ulcerations. Also, in fewer cases, the patient may evolve to subglottic stenosis, presenting symptoms such as dyspnea and stridor.

\section{CASE REPORT}

A 33 year old woman diagnosed with granulomatosis with polyangiitis since 2017 started out her symptoms with peripheral arthritis and diffuse arthralgia in 2016. The patient progressed to nosebleeds associated to nasal septum necrosis and saddle nose deformity. Diagnosis was confirmed by nasal septum biopsy and C-ANCA test positivity and treatment started with cyclophosphamide and prednisone.

Initially, treatment had partial control over the disease, yet the patient's overall condition worsened, leading to productive cough, dyspnea and the presence of abscesses and ulcerations. Hospitalization was necessary in December 2018 for a 28 day antibiotic course. Because of the non responsivity to cyclophosphamide and the severity of the pulmonary involvement, prednisone was maintained and treatment with mycophenolate mofetil, rituximab and prophylaxis for pulmonary infections was started.

In April 2019, the patient sought medical attention due to laryngeal stridor, dyspnea and episodes of visual turbidity and vertigo. Bronchoscopy indicated partial scar stenosis with approximately $1,5 \mathrm{~cm}$ in the subglottic region, resulting in a diameter of about $0,3 \mathrm{~cm}$, not making it possible for the device to go further (Figure 1). Endoscopic dilation was performed in a surgical center, without complications and resolution of dyspnea symptoms (Figura 2).

\section{CONCLUSION}

Granulomatosis with polyangiitis is a disease that can be of difficult control and with a variety of clinical manifestations. This increases the importance of early diagnosis and continuous medical support in order to avoid severe complications. In this case report, the identification of the subglottic stenosis enabled resolution of the symptoms through endoscopic dilation, avoiding a possible tracheostomy.

Figure 1- Bronchoscopy before endoscopic dilatation 
Figure 2- Bronchoscopy after endoscopic dilatation 